\title{
CGRP may regulate bone metabolism through stimulating osteoblast differentiation and inhibiting osteoclast formation
}

\author{
HAITAO HE ${ }^{1}$, JIANSHEN CHAI ${ }^{1}$, SHENGFU ZHANG ${ }^{1}$, LINLIN DING ${ }^{1}$, \\ PENG YAN ${ }^{1}$, WENJUN DU ${ }^{1}$ and ZHENZHOU YANG ${ }^{2}$ \\ ${ }^{1}$ Department of Maxillofacial and Head and Neck Surgery, Daping Hospital and Research Institute of Surgery; \\ ${ }^{2}$ Department of Oncology, Cancer Center, Daping Hospital and Research Institute of Surgery, \\ Third Military Medical University, Chongqing 400042, P.R. China
}

Received April 16, 2015; Accepted March 3, 2016

DOI: $10.3892 / \mathrm{mmr} .2016 .5023$

\begin{abstract}
Calcitonin-gene-related peptide (CGRP) is a neuropeptide, which is widely distributed throughout the central and peripheral nervous systems. Numerous mechanisms underlying the action of CGRP in osteoblast-associated cells have been suggested for bone growth and metabolism. The present study was designed to closely investigate the osteoblast- and osteoclast-associated mechanisms of the effect of CGRP administration on bone metabolism in primary osteoblasts. Primary osteoblasts were obtained from newborn rabbit calvaria and incubated with different concentrations of human CGRP (hCGRP), hCGRP and hCGRP (8-37), or without treatment as a control. Intracellular calcium $\left(\mathrm{Ca}^{2+}\right)$ and cyclic adenosine monophosphate (cAMP) were detected following treatment, as well as the expression levels of osteoblast differentiation markers, including activating transcription factor-4 (ATF4) and osteocalcin (OC), and receptor activator of nuclear factor $\kappa \mathrm{B}$ ligand (RANKL) and osteoprotegerin (OPG). The isolated primary osteoblasts were found to stain positively for ALP. hCGRP treatment had no significant effect on transient intracellular $\mathrm{Ca}^{2+}$ in the osteoblasts. Treatment of the osteoblasts with hCGRP led to elevations in the expression levels of cAMP, ATF4 and OPG, and downregulation in the expression of RANKL, in a dose-dependent manner. These effects were markedly reversed by the addition of hCGRP (8-37). The results of the present study demonstrated that CGRP administration not only stimulated osteoblast differentiation, as demonstrated by upregulated expression levels of ATF4
\end{abstract}

Correspondence to: Dr Zhenzhou Yang, Department of Oncology, Cancer Center, Daping Hospital and Research Institute of Surgery, Third Military Medical University, 10 Changjiang Branch Road, Daping, Yuzhong, Chongqing 400042, P.R. China

E-mail: zhenzhouyang21@163.com

Key words: calcitonin-gene-related peptide, osteoblast, calcium, cyclic adenosine monophosphate, activating transcription factor-4, osteocalcin, osteoprotegerin, receptor activator of nuclear factor $\kappa \mathrm{B}$ ligand and OC in the hCGRP-treated osteoblasts, but also inhibited OPG/RANKL-regulated osteoclastogenesis. CGRP may act as a modulator of bone metabolism through osteoblast and osteoclast-associated mechanisms, which result in osteoblast formation with subsequent activation of bone formation.

\section{Introduction}

Calcitonin gene-related peptide (CGRP), a 37-residue peptide produced in specific neurons by alternative splicing of the calcitonin gene, is an important neuropeptide involved in bone growth and metabolism (1). Previous studies have provided evidence suggesting that CGRP innervation is associated with bone formation $(2,3)$. CGRP can stimulate the proliferation and differentiation of osteoblasts, and improve bone fracture healing and bone metabolism (4). The overexpression of CGRP in the osteoblasts of transgenic mice has been shown to increase bone density (5). Valentijn et al indicated that CGRP administration inhibited bone resorption, but not bone formation, in ovariectomized rats (6). In a previous study by Schinke et al, it was shown that $\alpha$-CGRP only regulated the functional activity of osteoblasts in vivo (7). Another study indicated that CGRP may modulate the balance between osteoblast and osteoclast activity, which is involved in fine-tuning all the bone remodeling phases necessary for the subsequent anabolic effect (8).

The interaction of CGRP with specific G-protein-coupled receptors is known to activate multiple signaling transduction pathways. Numerous mechanisms of action of CGRP in osteoblast-associated cells have been suggested for bone growth and metabolism $(4,9,10)$. However, the detailed regulatory mechanism underlying the effect of CGRP in bone metabolism remains to be fully elucidated. The expression of osteocalcin (OC) is parallel with osteogenic differentiation and is utilized as a characteristic marker of osteogenic differentiation. Treatment with CGRP increases the mRNA expression of $\mathrm{OC}$ and has been suggested to induce osteoblast differentiation (11). Activating transcription factor-4 (ATF4), also known as cyclic adenosine monophosphate (cAMP)-response element-binding protein 2 (CREB2), is a leucine zipper-containing transcription factor, which regulates OC transcription and osteoblast 
terminal differentiation. However, the detailed effects of CGRP treatment on the expression of ATF4 has not been investigated previously.

The receptor activator of nuclear factor $\kappa \mathrm{B}$ ligand (RANKL) and osteoprotegerin (OPG) are important transcription factors in the regulation of bone formation and resorption (12-14). The balance between RANKL and OPG is a critical determinant for osteoclast differentiation. Neuropeptide CGRP has been reported to be important in suppressing bone resorptive activities through the RANKL/OPG pathway (15). However, CGRP administration has also demonstrated a significant depressive effect on the expression of RANKL, without an effect on the expression of OPG in primary human osteoblasts (16). Furthermore, a study by Villa et al found that CGRP inhibited OPG production in human osteoblast-like cells, with no detectable expression of RANKL (8). The present study was performed to further clarify the potential mechanism of CGRP on bone metabolism in primary osteoblasts, predominantly focussing on the osteoblast- and osteoclast-associated mechanisms.

\section{Materials and methods}

Cell isolation and identification. Primary osteoblasts were digested from newborn Chinese rabbit (purchased from Shanghai SLAC Laboratory Animal Co., Ltd., Shanghai, China) calvaria using a method described previously (17). Briefly, the calvaria were dissected from 8 newly born Chinese rabbits at $<24 \mathrm{~h}$ of age (weight, 60-120 g; male and female), and subjected to sequential digestion with $0.25 \%$ trypsin (Gibco; Thermo Fisher Scientific, Inc., Waltham, MA, USA) and $0.15 \%$ collagenase II (Sigma-Aldrich, St. Louis, MO, USA) at $37^{\circ} \mathrm{C}$ for 15 and $60 \mathrm{~min}$, respectively. Osteoblasts were collected following centrifugation at $2,000 \mathrm{x}$ g at $4^{\circ} \mathrm{C}$ for $5 \mathrm{~min}$ and a second collagenase digestion step, and were resuspended in Dulbecco's modified Eagle's medium (DMEM; Gibco; Thermo Fisher Scientific, Inc.) supplemented with $15 \%$ fetal bovine serum (Gibco; Thermo Fisher Scientific, Inc.). The cells were then counted using a hemocytometer (Baxter, Deerfield, IL, USA). The suspension was inoculated into a $100 \mathrm{ml}$ culture flask at a density of $5 \times 10^{5}$ cells $/ \mathrm{ml}$, cultured at $37^{\circ} \mathrm{C}$ in a humidified incubator with $5 \% \mathrm{CO}_{2}$, and passaged every 2-3 days. The enriched osteoblasts were purified using a differential adhesion method, where cells were cultured for $10 \mathrm{~min}$ at $37^{\circ} \mathrm{C}$ in $5 \% \mathrm{CO}_{2}$ to allow adherence of fibroblasts to the surface of the flask. The cells suspended in the medium were then moved to fresh medium and cultured to obtain purified osteoblasts. Then, alkaline phosphatase (ALP) activity was examined using a modified Gomori calcium-cobalt method to identify the osteoblasts, where cells were fixed with 4\% paraformaldehyde (Beijing Chemical Reagent Company, Beijing, China), rinsed with distilled water 3 times, placed in an incubation solution at $37^{\circ} \mathrm{C}$ for $4 \mathrm{~h}$ and washed with running water for $10 \mathrm{~min}$. The cells were then incubated with cobalt nitrate solution (20 g/l; Sigma-Aldrich) for $5 \mathrm{~min}$, washed with running water, incubated with sulfurated amine solution $(10 \mathrm{~g} / \mathrm{l}$; Chongqing Huabo Co., Ltd., Chongqing, China) for $2 \mathrm{~min}$, and washed with running water. The cells were counter-stained with eosin (Sigma-Aldrich) and dried (18). The present study was ethically approved by the Animal Care Committee of the Third Military Medical University (Daping, China).
hCGRP treatment. Osteoblasts $\left(1 \times 10^{5}\right.$ cells $\left./ \mathrm{ml}\right)$ at passage five were incubated in serum-free DMEM culture medium for $24 \mathrm{~h}$ at $37^{\circ} \mathrm{C}$ to induce synchronization at the G0 phase, in order to compare the effect of hCHRP treatment on bone metabolism in primary osteoblasts. The synchronized cells were then distributed into six groups and cultured for $24 \mathrm{~h}$ at $37^{\circ} \mathrm{C}$ under the following conditions: Group 1, DMEM only as a negative control; Group 2, DMEM with $10^{-9} \mathrm{~mol} / \mathrm{l} \mathrm{hCGRP}$ and $10^{-6} \mathrm{~mol} / 1$ hCGRP (8-37) (both purchased from Sigma-Aldrich); Group 3, DMEM with $10^{-9} \mathrm{~mol} / 1 \mathrm{hCGRP}$; Group 4, DMEM with $10^{-8} \mathrm{~mol} / \mathrm{l}$ hCGRP; Group 5, DMEM with $10^{-7} \mathrm{~mol} / \mathrm{l}$ hCGRP; Group 6, DMEM with $10^{-10} \mathrm{~mol} / \mathrm{l}$ hCGRP.

Intracellular $\mathrm{Ca}^{2+}$ measurement. The osteoblasts were seeded at a density of $1 \times 10^{5} / \mathrm{ml}$ in each well of a 6 -plate, cultured until $70-80 \%$ confluence, and incubated for $24 \mathrm{~h}$ at $37^{\circ} \mathrm{C}$ in serum-free medium. The cells were then incubated in a working solution containing Fluo-3/AM ( $5 \mu \mathrm{mol} / 1$; Sigma-Aldrich) and Pluronic F-127 (18\%; Sigma-Aldrich) at $37^{\circ} \mathrm{C}, 5 \% \mathrm{CO}_{2}$ for $30 \mathrm{~min}$. The cells were then washed with $\mathrm{Ca}^{2+}$-free DMEM 2-3 times, re-suspended in $\mathrm{Ca}^{2+}$-free DMEM, and incubated for another $15 \mathrm{~min}$. The Fluo-3 fluorescence responses to intracellular $\mathrm{Ca}^{2+}$ concentrations were detected immediately after the addition of hCGRP or hCGRP (8-37), according to the group design, under a laser scanning confocal microscope (LSCM; Leica TCS NT type; Leica Microystems GmbH, Wetzlar, Germany).

cAMP radioimmunoassay. The synchronized osteoblasts were treated with the phosphodiesterase inhibitor, 3-isobutyl-1-methylxanthine (0.5 $\mu \mathrm{mol} / \mathrm{l}$; Sigma-Aldrich)) for $15 \mathrm{~min}$, and were then incubated with different concentrations of hCGRP and hCGRP (8-37) for $10 \mathrm{~min}$ at $37^{\circ} \mathrm{C}$, or without treatment, according to the particular treatment group. The levels of cAMP were assayed using a commercial cAMP assay kit (Nuclear Medicine Laboratory of Shanghai University of Traditional Chinese Medicine, Shanghai, China), according to the manufacturer's protocol.

Electrophoretic mobility shift assay (EMSA). Following treatment of the osteoblasts in each group for $24 \mathrm{~h}$, nuclear extracts were isolated for EMSA analysis. Briefly, cells were harvested and resuspended in $1 \mathrm{ml}$ cold buffer A [10 mmol/l $\mathrm{KCl}, 1.5 \mathrm{mmol} / 1 \mathrm{MgCl}_{2}, 1 \mathrm{mmol} / 1$ dithiothreitol (DTT), $0.2 \mathrm{mmol} / \mathrm{l}$ ethylenediaminetetraacetic acid (EDTA), $1 \mathrm{mmol} / 1$ phenylmethylsulfonyl fluoride (PMSF), 5\% glycerinum, $3 \mathrm{mg} / \mathrm{l}$ aprotinin, $3 \mathrm{mg} / 1$ phenanthroline, $1 \% \mathrm{NP} 40$ and $10 \mathrm{mmol} / 1$ HEPES] and homogenized. The cells were then placed on ice for $15 \mathrm{~min}$ and centrifuged at $16,000 \mathrm{x} \mathrm{g}$ for $15 \mathrm{~min}$. The cell pellets were gently resuspended in $500 \mu \mathrm{l}$ buffer B (420 mmol/1 $\mathrm{NaCl}, 1.5 \mathrm{mmol} / 1 \mathrm{MgCl}_{2}, 0.5 \mathrm{mmol} / 1 \mathrm{DTT}, 0.2 \mathrm{mmol} / \mathrm{l}$ EDTA, $0.5 \mathrm{mmol} / 1 \mathrm{PMSF}, 25 \%$ glycerinum, $5 \mathrm{mg} / \mathrm{l}$ aprotinin, $5 \mathrm{mg} / \mathrm{l}$ phenanthroline, $3 \mathrm{mg} / \mathrm{l}$ pepstatin A and $20 \mathrm{mmol} / \mathrm{l} \mathrm{HEPES}$ ), vortex blended for $15 \mathrm{sec}$ and placed on ice for $10 \mathrm{~min}$. The procedures were repeated for 4 times, then the nuclear lysates were centrifuged at $16,000 \mathrm{x}$ g for $15 \mathrm{~min}$, aliquoted, and stored at $-80^{\circ} \mathrm{C}$. The protein concentrations were measured using the Bradford method (19). The oligonucleotide sequences used as the ATF4 probe (5-AGGACGAATGTAGTCTCTC-3) was synthesized by Shanghai Shenggong Bioengineering Co., 
Table I. Probes used for northern blot analysis.

\begin{tabular}{llc}
\hline Gene & \multicolumn{1}{c}{ Sequence $\left(5^{\prime}-3 '\right)$} & Length (bp) \\
\hline RANKL-1 & TTCAGCCCTTTGCCCATCTCACGA & 24 \\
RANKL-2 & AAGTCGGGAAACGGGTAGAGTGCT & 24 \\
OC-1 & TCTCTCTAGCCCAGCACCCTCCCC & 24 \\
OC-2 & AGAGAGATCGGGTCGTGGGAGGGG \\
OPG-1 & TCCTCTCTACACTCTCTGCGTTTACTTTGGTGC & 24 \\
OPG-2 & AGGAGAGATGTGAGAGACGCAAATGAAACCACG & 33 \\
$\beta$-actin-1 & CCACCAGACAGCACTGTGTTGGCA & 33 \\
$\beta$-aactin-2 & GGTGGTCTGTCGTGACACAACCGT & 24 \\
\hline
\end{tabular}

RANKL, receptor activator of nuclear factor $\kappa \mathrm{B}$ ligand; OC, osteocalcin; $\mathrm{OPG}$, osteoprotegerin.

Ltd. (Shanghai, China) and was end-labeled using $\gamma-{ }^{32} \mathrm{p}-\mathrm{ATP}$ (Beijing Furui Biotech Co., Ltd., Beijing, China). For the specific competitive experiment, a molar excess of unlabeled ATF4 oligonucleotide was added to the binding reaction, together with the labeled ATF4 probe. For the super shift assay, polyclonal rabbit anti-ATF4 antibody (1:200 dilution; sc-22800; Santa Cruz Biotechnology, Inc., Dallas, TX, USA) was incubated with the nuclear extracts prior to the addition of the other components for $20 \mathrm{~min}$ at $37^{\circ} \mathrm{C}$. The Light Shift Chemiluminescent Electrophoretic Mobility Shift Assay kit (Pierce Biotechnology, Inc., Rockford, IL, USA) was used to perform EMSA, as described previously (20). The samples $(1.7 \mu \mathrm{g} / \mu \mathrm{l})$ were separated by electrophoresis on a $6 \%$ polyacrylamide gel (Promega Corporation, Madison, WI, USA) and analyzed using the Tanon GIS-2010 image analysis system (Shanghai Tanon Science \& Technology Co., Ltd., Shanghai, China).

Northern blot analysis. Total RNA was extracted from the osteoblasts using a modified guanidinium isothiocyanate method (21). Briefly, cells were resuspended in $1 \mathrm{ml}$ guanidinium thiocyanate buffer $(4 \mathrm{~mol} / \mathrm{l}$; Fluka Chemical Corporation, Hauppauge, NY, USA) at $4^{\circ} \mathrm{C}$ for $5 \mathrm{~min}$ and ultrasonicated for $5 \sec 3$ times. Chloroform (100 $\mu \mathrm{l}$; Tianjin Hengxing Chemical Reagent Co., Ltd., Tianjin, China) was added to each tube, vibrated, and maintained at $4{ }^{\circ} \mathrm{C}$ for $10 \mathrm{~min}$. Following centrifugation at $12,000 \mathrm{x} \mathrm{g}$ for $15 \mathrm{~min}$ at $4^{\circ} \mathrm{C}$, supernatants were collected, to which equal volumes of isopropanol (Beijing Baishun Chemical Technology Co., Ltd., Beijing, China), precooled at $-20^{\circ} \mathrm{C}$, were added and blended. The mixture was then centrifuged at $12,000 \mathrm{x} \mathrm{g}$ for $10 \mathrm{~min}$ at $4^{\circ} \mathrm{C}$. The pellets were washed with $80 \%$ ethanol $(0.5 \mathrm{ml})$ for $5 \mathrm{sec}$ and centrifuged at 7,500 $\mathrm{x}$ g for $5 \mathrm{~min}$ at $4^{\circ} \mathrm{C}$. The final pellets were dried in a DNA-mini vacuum dryer (Bio-Rad Laboratories, Inc., Hercules, CA, USA) and dissolved in $30 \mu \mathrm{l}$ diethylpyrocarbonate ultrapure water. For quantitative analysis, the purity and concentration of the mRNA was measured using a Ultraviolet-visible Beckman DU 640 spectrophotometer (Beckman Coulter, Inc., Brea, CA, USA). The RNA $(5.4 \mu \mathrm{g} / \mu \mathrm{l})$ was separated on a urea-polyacrylamide gel electrophoresis (PAGE) gel and transferred onto a nitrocellulose membrane (Bio-Rad Laboratories, Inc.). Hybridization was performed according to a standard protocol. Following hybridization, the membranes were washed 3 times with hybridization stringency washing buffer (Pierce Biotechnology, Inc.), and the probe was detected with horseradish peroxidase (HRP) using a North2South Chemiluminescent Hybridization kit (Pierce Biotechnology, Inc.). The probes used are summarized in Table I.

Western blot analysis. The protein expression levels of ATF4, OC, RANKL and OPG was evaluated using Western blot analysis. Briefly, the cells were harvested and lysed using a Radioimmunoprecipitation kit (Shanghai Shenneng Bocai Biotechnology Co., Ltd., Shanghai, China), and protein concentration was determined using Coomassie Brilliant Blue staining (Sigma-Aldrich) and a Beckman DU 640 ultraviolet spectrophotometer. The protein samples $(15 \mu \mathrm{l})$ were subjected to SDS-PAGE (11\%; Sigma-Aldrich) and transferred onto a polyvinylidene fluoride membrane (DuPont, Boston, MA, USA). The membrane was blocked with $5 \%$ nonfat dry milk for $2 \mathrm{~h}$, and then incubated at $4^{\circ} \mathrm{C}$ overnight with primary antibodies against ATF4, OC, RANKL and OPG (1:200; Santa Cruz Biotechnology, Inc.), followed by incubation with the HRP-conjugated secondary antibodies $(1: 2,500$; Santa Cruz Biotechnology, Inc.). The blots were visualized using an ECL Western Blotting Substrate kit (Pierce Biotechnology, Inc.). The mRNA expression levels were quantified using a Beckman DU 640 ultraviolet spectrophotometer. The protein expression of $\beta$-actin was used as an internal control.

Statistical analysis. Data are expressed as the mean \pm standard deviation, and were subjected to one-way analysis of variance. $\mathrm{P} \leq 0.05$ was considered to indicate a statistically significant difference.

\section{Results}

Isolation and identification of osteoblasts. Primary osteoblasts were obtained from newborn rabbit calvaria and, following culture for $24 \mathrm{~h}$, the osteoblasts adhered to the walls, and exhibited a spindle-like, triangular or polyangular appearance (Fig. 1A and B). The cells exhibited a typical cobblestone morphology at confluence, and were positively stained for ALP (Fig. 1C and D). Following five passages, the osteoblasts exhibited a positivity of $>95 \%$. 

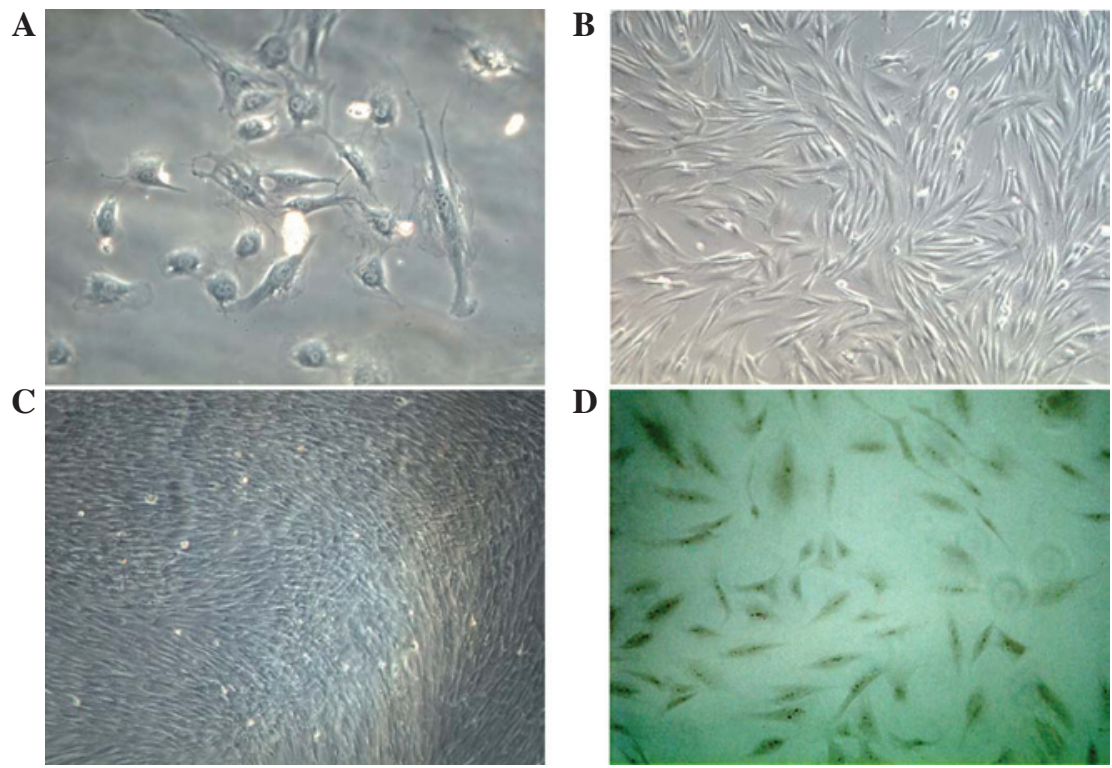

Figure 1. Morphology and characterization of osteoblasts isolated from newborn rabbit calvaria. (A) Cell morphology of primary osteoblasts following $24 \mathrm{~h}$ cultivation (magnification, x200). (B) Confluent growth of osteoblasts (magnification, x100). (C) Typical cobblestone morphology of osteoblasts at confluence. (magnification, x100). (D) Osteoblasts were positively stained for ALP. (magnification, x100).
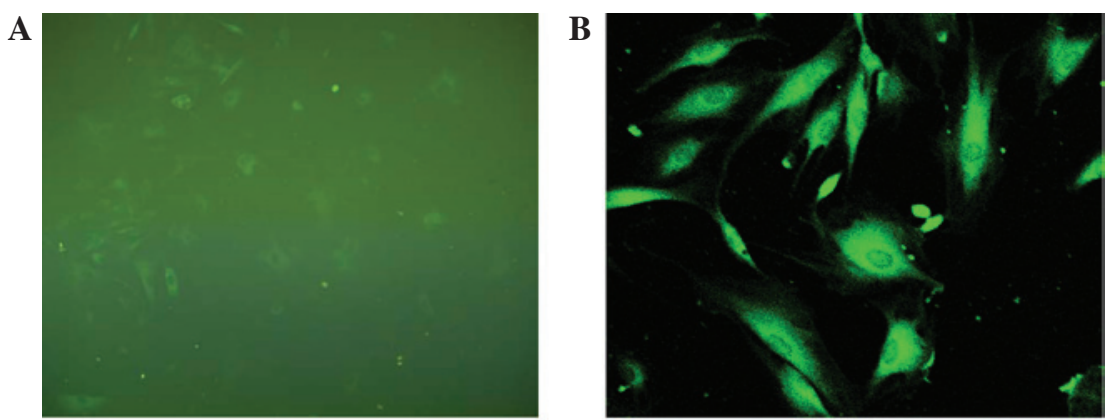

C

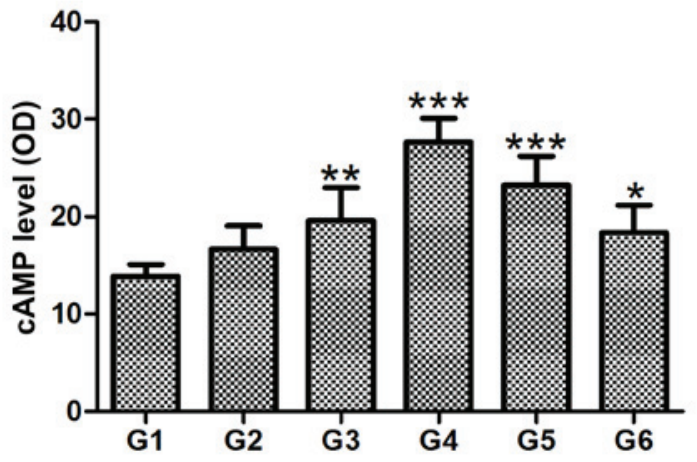

Figure 2. Effect of chumanalcitonin-gene-related peptide (hCGRP) treatment on intracellular levels of $\mathrm{Ca}^{2+}$ and cAMP in isolated osteoblasts. Fluo-3 AM was successfully loaded into the osteoblast, as demonstrated by (A) immunofluorescence microscopy (magnification, x100) and (B) laser scanning confocal microscopy (magnification, x200). (C) hCGRP treatment upregulated the levels of cAMP in a dose-dependent manner, and this effect was reversed by the selective antagonist of CGRP receptors, hCGRP (8-37). Data are expressed as the mean \pm standard deviation $(\mathrm{n}=4) .{ }^{*} \mathrm{P}<0.05,{ }^{* *} \mathrm{P}<0.001$ and ${ }^{* * * *} \mathrm{P}<0.0001$ vs. control. G1, osteoblasts cultured in Dulbecco's modified Eagle's medium (DMEM) only as a negative control; G2, osteoblasts cultured in DMEM with $10^{-9} \mathrm{~mol} / 1 \mathrm{hCGRP}$ and $10^{-6} \mathrm{~mol} / 1 \mathrm{hCGRP}(8-37)$; G3, osteoblasts cultured in DMEM with $10^{-9} \mathrm{~mol} / \mathrm{l} \mathrm{hCGRP;} \mathrm{G4,} \mathrm{osteoblasts} \mathrm{cultured} \mathrm{in} \mathrm{DMEM} \mathrm{with} 10^{-8} \mathrm{~mol} / \mathrm{l}$ hCGRP; G5, osteoblasts cultured in DMEM with $10^{-7} \mathrm{~mol} / 1$ hCGRP; G6, osteoblasts cultured in DMEM with $10^{-10} \mathrm{~mol} / 1 \mathrm{hCGRP}$; cAMP, cyclic adenosine monophosphate; OD, optical density.

hCGRP induces increases in cAMP, but has no effect on intracellular $\mathrm{Ca}^{2+}$. Intracellular $\mathrm{Ca}^{2+}$ measurements were performed following treatment of the osteoblasts with hCGRP, and the fluorescence intensity and distribution of $\mathrm{Ca}^{2+}$ fluorescence signal in single cells were measured using
LSCM. The cells were successfully loaded with the Fluo-3/AM $\mathrm{Ca}^{2+}$-sensitive dye; exhibiting a bright cytoplasm and dark nucleus under immunofluorescence microscopy and LSCM, respectively (Fig. 2A and B). hCGRP caused no significant effect on transient intracellular $\mathrm{Ca}^{2+}$ in the osteoblasts (data not 

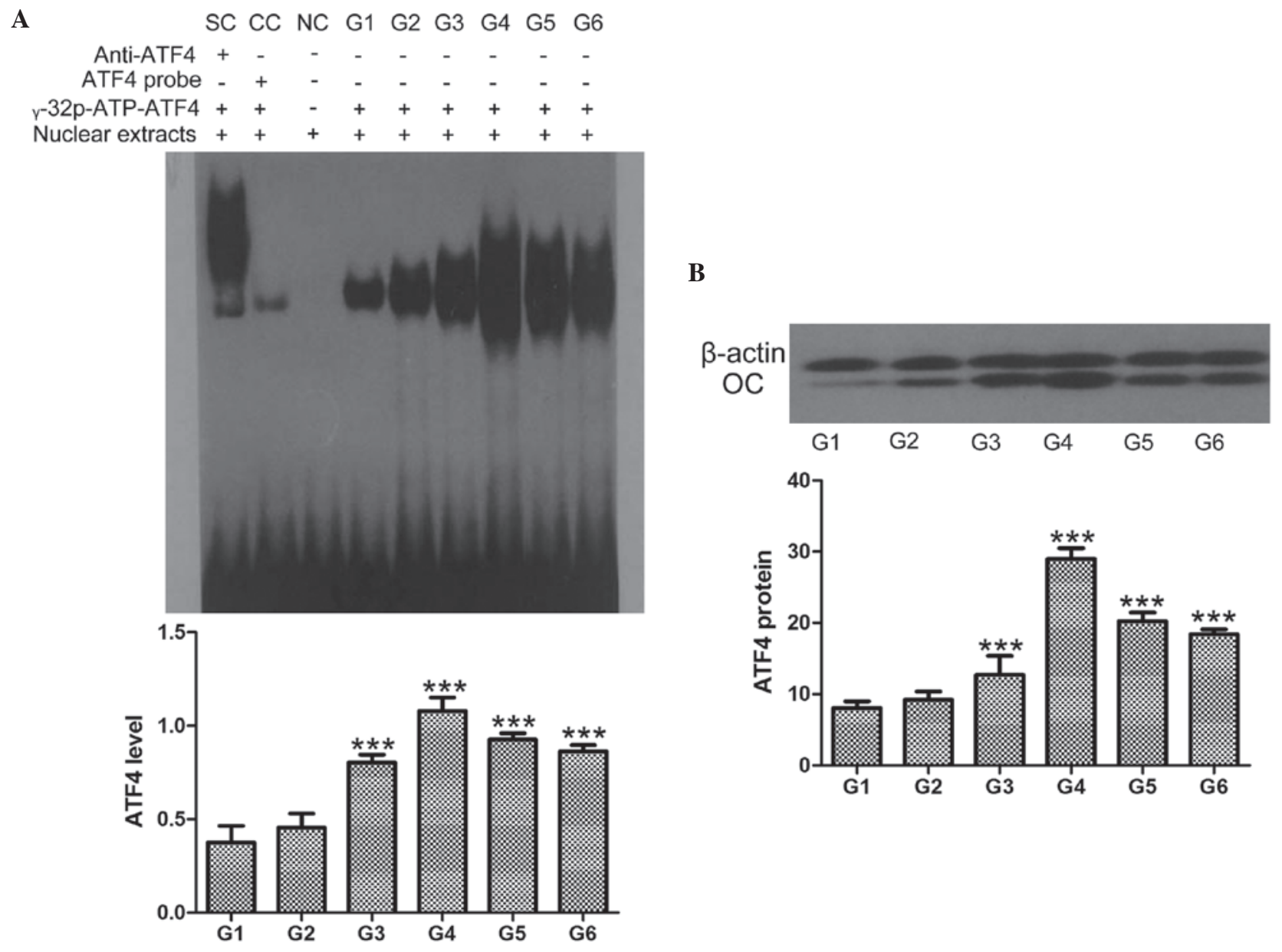

Figure 3. Effect of chumanalcitonin-gene-related peptide (hCGRP) treatment on the expression of ATF4 in isolated osteoblasts. (A) EMSA assay of ATF4 activity following treatment with hCGRP and column diagram of ATF4 activity. (B) Western blot analysis of the expression of ATF4 following treatment with hCGRP and column diagram of the expression of ATF4. Data are expressed as the mean \pm standard deviation. ${ }^{* * *} \mathrm{P}<0.001$, vs. control group. G1, osteoblasts cultured in Dulbecco's modified Eagle's medium (DMEM) only as a negative control; G2, osteoblasts cultured in DMEM with $10^{-9}$ mol/1 hCGRP and $10^{-6}$ mol/1 hCGRP (8-37); G3, osteoblasts cultured in DMEM with $10^{-9} \mathrm{~mol} / 1$ hCGRP; G4, osteoblasts cultured in DMEM with 10 ${ }^{-8}$ mol/1 hCGRP; G5, osteoblasts cultured in DMEM with $10^{-7} \mathrm{~mol} / 1$ hCGRP; G6, osteoblasts cultured in DMEM with $10^{-10}$ mol/1 hCGRP; ATF4, activating transcription factor-4; OD, optical density; OC, osteocalcin; SC, supershift using anti-ATF4 antibody; CC, competition control using unlabeled ATF4 probe; NC, negative control without nuclear extracts.

shown). Compared with the control group, intracellular levels of cAMP in the cells treated with hCGRP were significantly increased, and peaked at a hCGRP concentration of $10^{-9} \mathrm{~mol} / \mathrm{l}$ $(\mathrm{P}<0.01)$. This hCGRP-stimulated increase in cAMP content was inhibited by the selective antagonist of CGRP receptors, hCGRP (8-37), as shown in Fig. 2C.

hCGRP induces the activation of ATF4. As shown in Fig. 3, treatment of osteoblasts with hCGRP led to the accumulation of ATF4 in the nuclei of the cells, in a dose-dependent manner, and the maximum activation of ATF4 was obtained at the hCGRP concentration of $10^{-8} \mathrm{~mol} / \mathrm{l}$. This effect was markedly reversed by the addition of hCGRP (8-37), as shown in Fig. 3A $(\mathrm{P}<0.05)$. Similarly, the protein expression of ATF4 in the osteoblasts was also significantly enhanced following hCGRP treatment, and treatment with hCGRP (8-37) compromised this hCGRP-induced upregulation of ATF4 (P<0.05; Fig. 3B).

hCGRP induces the levels of $O C$ and $O P G$, and inhibits the level of RANKL in osteoblasts. Northern blot and western blot analyses were performed to determine the expression levels of
OC, OPG and RANKL in the osteoblasts following treatment with hCGRP. The results showed that the expression levels of OC and OPG were significantly upregulated by hCGRP at the mRNA and protein levels, whereas the expression of RANKL was markedly downregulated. These effects were significantly counteracted by hCGRP (8-37) administration (Figs. 4 and 5).

\section{Discussion}

As a multifunctional regulatory neuropeptide, CGRP is known to be involved in bone formation, metabolism, healing and remodeling. The potential mechanisms have been examined extensively, and cAMP-related pathways have been reported to be involved in CGRP-regulated bone metabolism, and CGRP-induced cAMP accumulation in osteoblastic cells (22). Pretreatment with the cAMP pathway inhibitor, H89, can eliminate the CGRP-induced increases in the level of cAMP and expression of bone morphogenetic protein-2 (23). By contrast, the absence of cAMP formation has also been reported following CGRP treatment (12). The findings of the present study showed that hCGRP treatment caused a significant 

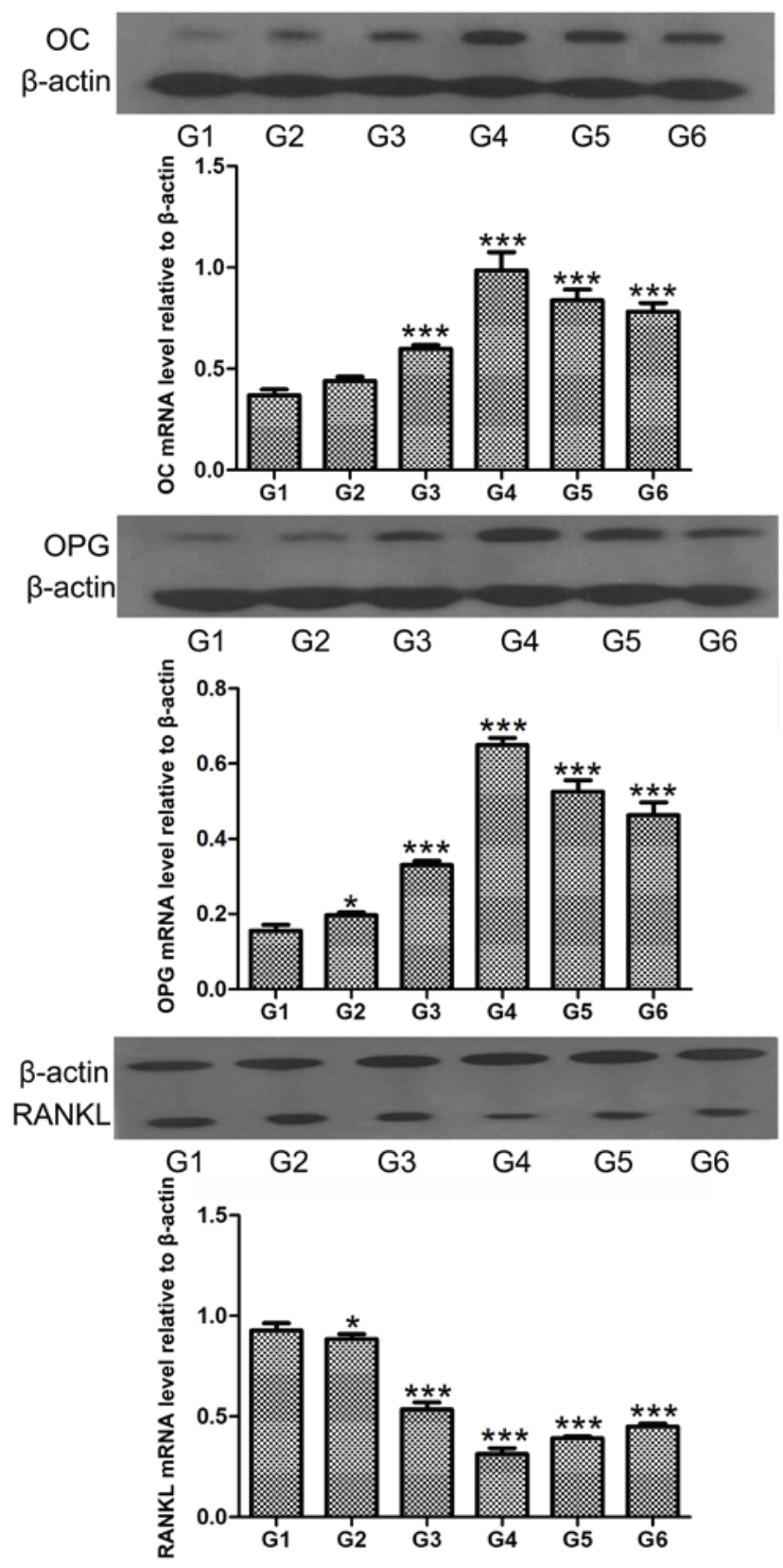

Figure 4. Northern blot analysis of the effect of chumanalcitonin-gene-related peptide (hCGRP) treatment on the mRNA expression levels of osteocalcin, OPG and RANKL in isolated osteoblasts. G1, osteoblasts cultured in Dulbecco's modified Eagle's medium (DMEM) only as a negative control; G2, osteoblasts cultured in DMEM with $10^{-9} \mathrm{~mol} / \mathrm{l} \mathrm{hCGRP}$ and $10^{-6} \mathrm{~mol} / \mathrm{l}$ hCGRP (8-37); G3, osteoblasts cultured in DMEM with $10^{-9} \mathrm{~mol} / 1$ hCGRP; G4, osteoblasts cultured in DMEM with $10^{-8} \mathrm{~mol} / \mathrm{l}$ hCGRP; G5, osteoblasts cultured in DMEM with $10^{-7} \mathrm{~mol} / 1$ hCGRP; G6, osteoblasts cultured in DMEM with $10^{-10} \mathrm{~mol} / 1 \mathrm{hCGRP}$. Data are expressed as the mean \pm standard deviation. ${ }^{*} \mathrm{P}<0.05$ and ${ }^{* * *} \mathrm{P}<0.001$, vs. control group. OC, osteocalcin; OPG, osteoprotegerin; RANKL, receptor activator of nuclear factor $\kappa \mathrm{B}$ ligand.

accumulation of cAMP, in a dose-dependent manner, indicating that cAMP was involved in CGRP-regulated bone metabolism, and detailed investigations were performed to clarify this further.

CGRP has been reported to increase the intracellular levels of $\mathrm{Ca}^{2+}(24,25)$, whereas lower plasma levels of $\mathrm{Ca}^{2+}$ were identified in another study (26). A previous study
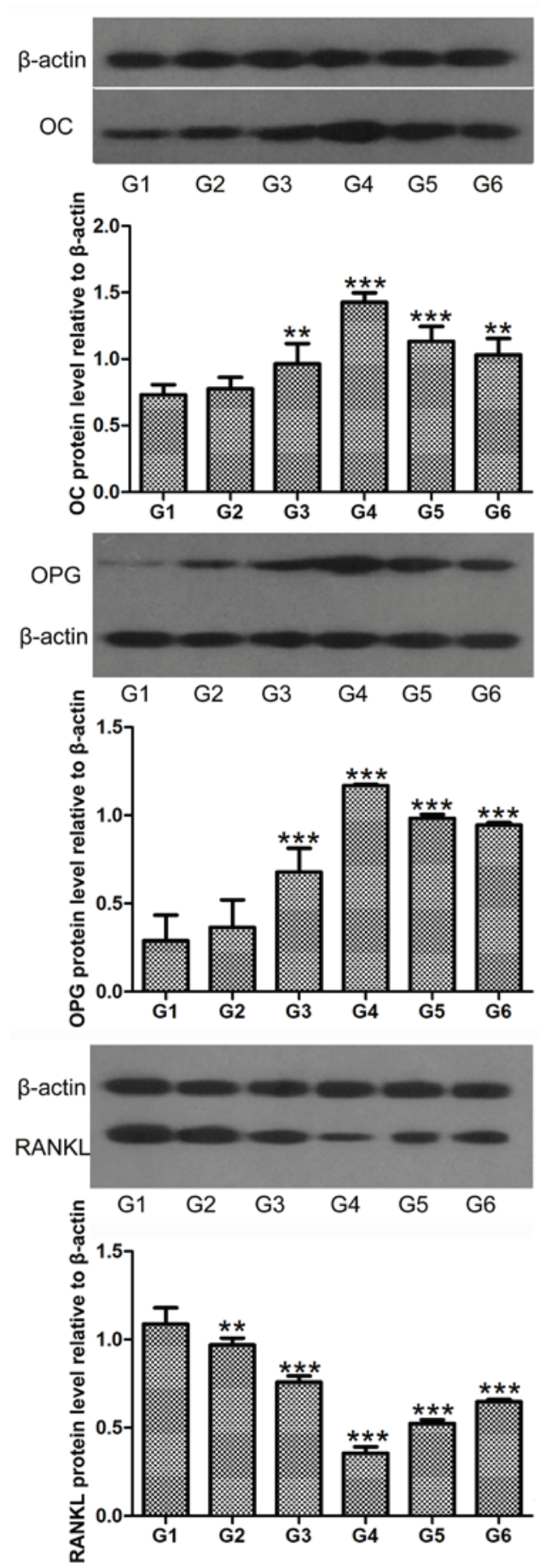

Figure 5. Western blot analysis of the effect of chumanalcitonin-gene-related peptide (hCGRP) treatment on the protein expression levels of OC, OPG and RANKL in isolated osteoblasts. Data are expressed as the mean \pm standard deviation. ${ }^{* * *} \mathrm{P}<0.01$ and $^{* * * *} \mathrm{P}<0.001$, vs. control group. G1, osteoblasts cultured in Dulbecco's modified Eagle's medium (DMEM) only as a negative control; G2, osteoblasts cultured in DMEM with $10^{-9} \mathrm{~mol} / \mathrm{l} \mathrm{hCGRP}$ and $10^{-6} \mathrm{~mol} / \mathrm{l}$ hCGRP (8-37); G3, osteoblasts cultured in DMEM with $10^{-9} \mathrm{~mol} / 1$ hCGRP; G4, osteoblasts cultured in DMEM with $10^{-8} \mathrm{~mol} / \mathrm{l}$ hCGRP; G5, osteoblasts cultured in DMEM with $10^{-7} \mathrm{~mol} / 1$ hCGRP; G6, osteoblasts cultured in DMEM with $10^{-10} \mathrm{~mol} / 1$ hCGRP; OC, osteocalcin; OPG, osteoprotegerin; RANKL, receptor activator of nuclear factor $\kappa \mathrm{B}$ ligand.

indicated that CGRP may elevate $\mathrm{Ca}^{2+}$ in MG-63 cells through cAMP-independent and cAMP-dependent mechanisms (27). To closely evaluate the effect of hCGRP on intracellular levels 
of $\mathrm{Ca}^{2+}$ in primary osteoblasts, LSCM was used to detect the intracellular concentrations of $\mathrm{Ca}^{2+}$ in the osteoblasts following hCGRP treatment. Unlike the results described above, these results showed no significant effect of CGRP on intracellular $\mathrm{Ca}^{2+}$ in the osteoblasts. These conflicting results can be partially explained by the specie and tissue specificities of the CGRP receptor, the interaction of receptor activity-modify proteins with the CGRP receptor $(28,29)$ or the phase of the cell cycle selected for investigation. In the present study, the osteoblasts were synchronized to the G0 phase by serum starvation, whereas cells in the S and G2 phases were used in the previous study reported by Drissi et al (12).

ATF4, a member of the ATF/CREB family, was originally identified as an osteoblast-specific transcription factor, required for the transcription of $\mathrm{OC}$, as in an osteoblast-specific marker routinely used as an important indicator of late-stage osteoblast differentiation (30). The expression of ATF4 is known to be required for osteoblast terminal differentiation and for maintaining mature osteoblast function (31). Activation of the cAMP-CREB signaling pathway by G-protein-coupled receptor 48 has been reported to regulate the expression levels of ATF4 and OC in osteoblasts (32). CGRP has been previously shown to upregulate the expression of OC (11). Consistent with these results, the present study showed enhanced mRNA and protein expression levels of ATF4 and OC following treatment of the osteoblasts with hCGRP, suggesting the inducing effect of CGPR on osteoblast differentiation.

As members of the tumor necrosis factor family, RANKL and OPG are critical in bone remodeling by directly controlling osteoclast differentiation and osteolysis (33). Previous studies have presented conflicting data regarding the effect of CGRP on the expression levels of OPG and RANKL in osteoblast-like cells. Villa et al found that CGRP favored osteoclastogenesis by inhibiting the production of OPG in human osteoblast-like cells via the cAMP/PKA-dependent pathway, without detectable effects on the expression of RANKL (8). By contrast, a study by Kauther et al showed a significant depressive effect of CGRP on the expression of RANKL, but not on the expression of OPG, in primary human osteoblasts (16). It has also been previously indicated that CGRP may suppress bone resorption through OPG stimulation and RANKL inhibition $(15,34)$. These results are consistent with the data obtained in the present study, which indicated that CGRP treatment altered the balance between the expression levels of OPG and RANKL towards a decline in RANKL, thus inhibiting osteoclast formation and function.

In conclusion, the findings of the present study presented evidence to suggest that CGRP administration not only stimulated osteoblast differentiation, as demonstrated by upregulated expression levels of ATF4 and OC in osteoblasts treated with hCGRP, but it also inhibited OPG/RANKL-regulated osteoclastogenesis. CGRP may act as a modulator of bone metabolism through osteoblast- and osteoclast-associated mechanisms, which favor osteoblast formation and the subsequent activation of bone formation.

\section{Acknowledgements}

The current study was financially supported by the National Natural Science Foundation of China (grant no. 30772436).

\section{References}

1. Offley SC, Guo TZ, Wei T, Clark JD, Vogel H, Lindsey DP, Jacobs CR, Yao W, Lane NE and Kingery WS: Capsaicin-sensitive sensory neurons contribute to the maintenance of trabecular bone integrity. J Bone Miner Res 20: 257-267, 2005.

2. Irie K, Hara-Irie F, Ozawa H and Yajima T: Calcitonin gene-related peptide (CGRP)-containing nerve fibers in bone tissue and their involvement in bone remodeling. Microsc Res Tech 58: 85-90, 2002.

3. Sample SJ, Heaton CM, Behan M, Bleedom JA, Racette MA, Hao Z and Muir P: Role of calcitonin gene-related peptide in functional adaptation of the skeleton. PLoS One 9: e113959, 2014.

4. Villa I, Melzi R, Pagani F, Ravasi F, Rubinacci A and Guidobono F: Effects of calcitonin gene-related peptide and amylin on human osteoblast-like cells proliferation. Eur J Pharmacol 409: 273-278, 2000.

5. Ballica R, Valentijn K, Khachatryan A, Guerder S, Kapadia S, Gundberg C, Gilligan J, Flavell RA and Vignery A: Targeted expression of calcitonin gene-related peptide to osteoblasts increases bone density in mice. J Bone Miner Res 14: 1067-1074, 1999.

6. Valentijn K, Gutow AP, Troiano N, Gundberg C, Gilligan JP and Vignery A: Effects of calcitonin gene-related peptide on bone turnover in ovariectomized rats. Bone 21: 269-274, 1997.

7. Schinke T, Liese S, Priemel M, Haberland M, Schilling AF, Catala-Lehnen P, Blicharski D, Rueger JM, Gagel RF, Emeson RB and Amling M: Decreased bone formation and osteopenia in mice lacking alpha-calcitonin gene-related peptide. J Bone Miner Res 19: 2049-2056, 2004.

8. Villa I, Mrak E, Rubinacci A, Ravasi F and Guidobono F: CGRP inhibits osteoprotegerin production in human osteoblast-like cells via cAMP/PKA-dependent pathway. Am J Physiol Cell Physiol 291: C529-C537, 2006.

9. Villa I, Dal Fiume C, Maestroni A, Rubinacci A, Ravasi F and Guidobono F: Human osteoblast-like cell proliferation induced by calcitonin-related peptides involves PKC activity. Am J Physiol Endocrinol Metab 284: E627-E633, 2003.

10. Naot D and Cornish J: The role of peptides and receptors of the calcitonin family in the regulation of bone metabolism. Bone 43: 813-818, 2008.

11. Bo Y, Yan L, Gang Z, Tao L and Yinghui T: Effect of calcitonin gene-related peptide on osteoblast differentiation in an osteoblast and endothelial cell co-culture system. Cell Biol Int 36: 909-915, 2012.

12. Drissi H, Lieberherr M, Hott M, Marie PJ and Lasmoles F: Calcitonin gene-related peptide (CGRP) increases intracellular free $\mathrm{Ca}^{2+}$ concentrations but not cyclic AMP formation in CGRP receptor-positive osteosarcoma cells (OHS-4). Cytokine 11: 200-207, 1999.

13. Matsuo K and Irie N: Osteoclast-osteoblast communication. Arch Biochem Biophys 473: 201-209, 2008.

14. Lacey DL, Timms E, Tan HL, Kelley MJ, Dunstan CR, Burgess T, Elliott R, Colombero A, Elliott G, Scully S, et al: Osteoprotegerin ligand is a cytokine that regulates osteoclast differentiation and activation. Cell 93: 165-176, 1998.

15. Yoo YM, Kwag JH, Kim KH and Kim CH: Effects of neuropeptides and mechanical loading on bone cell resorption in vitro. Int J Mol Sci 15: 5874-5883, 2014.

16. Kauther MD, Xu J and Wedemeyer C: Alpha-calcitonin gene-related peptide can reverse the catabolic influence of UHMWPE particles on RANKL expression in primary human osteoblasts. Int J Biol Sci 6: 525-536, 2010.

17. Zhang Y, Sun X, Sun G, Liu S and Wang L: DNA damage induced by fluoride in rat osteoblasts. Fluoride 39 191-194, 2006.

18. Li SH, Guo DZ, Li B, Yin HB, Li JK, Xiang JM and Deng GZ: The stimulatory effect of insulin-like growth factor-1 on the proliferation, differentiation and mineralisation of osteoblastic cells from Holstein cattle. Vet J 179: 430-436, 2009.

19. Bradford MM: A rapid and sensitive method for the quantitation of microgram quantities of protein utilizing the principle of protein-dye binding. Anal Biochem 72: 248-254, 1976.

20. Yu HT, Yu M, Li CY, Zhan YQ, Xu WX, Li YH, Li W, Wang ZD, $\mathrm{Ge} \mathrm{CH}$ and Yang XM: Specific expression and regulation of hepassocin in the liver and down-regulation of the correlation of HNFlalpha with decreased levels of hepassocin in human hepatocellular carcinoma. J Biol Chem 284: 13335-13347, 2009.

21. Chomczynski P and Sacchi N: Single-step method of RNA isolation by acid guanidinium thiocyanate-phenol-chloroform extraction. Anal Biochem 162: 156-159, 1987. 
22. Vignery A and McCarthy TL: The neuropeptide calcitonin gene-related peptide stimulates insulin-like growth factor I production by primary fetal rat osteoblasts. Bone 18: 331-335, 1996

23. Tian $G$, Zhang $\mathrm{G}$ and Tan YH: Calcitonin gene-related peptide stimulates BMP-2 expression and the differentiation of human osteoblast-like cells in vitro. Acta Pharmacol Sin 34: 1467-1474, 2013.

24. Kawase T, Howard GA, Roos BA and Burns DM: Diverse actions of calcitonin gene-related peptide on intracellular free $\mathrm{Ca}^{2+}$ concentrations in UMR 106 osteoblastic cells. Bone 16 (Suppl 4): S379-S384, 1995.

25. Bjurholm A, Kreicbergs A, Brodin E and Schultzberg M: Substance P- and CGRP-immunoreactive nerves in bone. Peptides 9: 165-171, 1988.

26. Tippins JR, Morris HR, Panico M, Etienne T, Bevis P, Girgis $S$ MacIntyre I, Azria M and Attinger M: The myotropic and plasma-calcium modulating effects of calcitonin gene-related peptide (CGRP). Neuropeptides 4: 425-434, 1984.

27. Burns DM, Stehno-Bittel L and Kawase T: Calcitonin gene-related peptide elevates calcium and polarizes membrane potential in MG-63 cells by both cAMP-independent and-dependent mechanisms. Am J Physiol Cell Physiol 287: C457-C467, 2004.

28. Katafuchi T, Kikumoto K, Hamano K, Kangawa K, Matsuo H and Minamino N: Calcitonin receptor-stimulating peptide, a new member of the calcitonin gene-related peptide family its isolation from porcine brain, structure, tissue distribution and biological activity. J Biol Chem 278: 12046-12054, 2003.
29. Born W, Fischer JA and Muff R: Receptors for calcitonin gene-related peptide, adrenomedullin and amylin: The contributions of novel receptor-activity-modifying proteins. Receptors Channels 8: 201-209, 2002.

30. Lian N, Lin T, Liu W, Wang W, Li L, Sun S, Nyman JS and Yang X: Transforming growth factor $\beta$ suppresses osteoblast differentiation via the vimentin activating transcription factor 4 (ATF4) axis. J Biol Chem 287: 35975-35984, 2012.

31. Yang X, Matsuda K, Bialek P, Jacquot S, Masuoka HC, Schinke T, Li L, Brancorsini S, Sassone-Corsi P, Townes TM, et al: ATF4 is a substrate of RSK2 and an essential regulator of osteoblast biology: Implication for Coffin-Lowry Syndrome. Cell 117: 387-398, 2004

32. Luo J, Zhou W, Zhou X, Li D, Weng J, Yi Z, Cho SG, Li C, Yi T, $\mathrm{Wu}$ X, et al: Regulation of bone formation and remodeling by G-protein-coupled receptor 48. Development 136: 2747-2756, 2009.

33. Angelopoulos NG, Goula A, Katounda E, Rombopoulos G, Kaltzidou V, Kaltsas D, Malaktari S, Athanasiou V and Tolis G: Circulating osteoprotegerin and receptor activator of NF-kappaB ligand system in patients with beta-thalassemia major. $\mathrm{J}$ Bone Miner Metab 25: 60-67, 2007.

34. Wang L, Shi X, Zhao R, Halloran BP, Clark DJ, Jacobs CR and Kingery WS: Calcitonin-gene-related peptide stimulates stromal cell osteogenic differentiation and inhibits RANKL induced NF-kappaB activation, osteoclastogenesis and bone resorption. Bone 46: 1369-1379, 2010. 